\title{
КЛАССИФИКАЦИЯ ПОНЯТИЙНОГО АППАРАТА В СИСТЕМЕ МЕНЕДЖМЕНТА
}

\begin{abstract}
Трошин Анатолий Сергеевич
К.э.н., дочент, ФГБОУ ВО «Волжский государственный университет водного транспорта»

tas-berkut@inbox.ru
\end{abstract}

CLASSIFICATION OF THE CONCEPTUAL APPARATUS IN THE MANAGEMENT SYSTEM

A. Troshin

E. Frantseva-Kostenko

Summary. The article deals with categorical distinctions of the main concepts of management theory, such as "management", "economic activity" , "business activity", etc., the problems of accuracy and clarity of definition of these economic categories, their retrospective formation and development, as well as their relationship and interdependence. The purpose of the article - based on the analysis of various sources to justify the objectivity and inevitability of intertwining these categories, where management plays a special role. The conclusion is that management theory develops along with the development of related economic categories

Keywords: management, management, economic activity, entrepreneurial activity, business.

$\mathbf{H}$ а современном этапе экономического развития в теории управления, особенно в России, активно обсуждаются вопросы, касающиеся самого понятия «менеджмент», а также его взаимосвязей с такими понятиями, как «хозяйственная деятельность», «экономическая деятельность», «предпринимательская деятельность» и др.

Для того, чтобы выявить и проследить взаимосвязь и взаимозависимость названных понятий обратимся к их трактовкам разными исследователями.

Легко предположить, что все эти понятия, хотя и в другом их понимании, появились в глубокой древности, когда, древнегреческие мыслители Ксенофонт (430354 г. до н.э.), Платон (428 (427) - 348 (347) гг. до н.э.), Аристотель (384-322 гг. до н.э.), описывали ведение и организацию хозяйства в поместье рабовладельцев. При этом, как широко известно, именно Аристотель дал и название современной экономической теории, назвав её «экономикой», что в переводе с греческого означает: «ойкос»- дом, хозяйство; «номос» - закон, учение.

Обратим внимание на то, что в своих трактатах древние мыслители рассуждали о разумном ведении хозяйства не только в собственных интересах, но и «в интересах людей» - полиса (города), сатрапии (региона), государства. При этом они рассуждали об уже существовавшей в тот период экономической деятельности, причём, деятельности в сфере материального производства, в аграрном секторе экономики. А создание, организация и ведение такой деятельности невозможны без её разумного регулирования и управления ею.

Скажем иначе, используя современную терминологию, процесс экономической, как и любого другого вида деятельности людей, всегда требует разумной организации, подчинения соответствующим экономи- 
ческим, этическим, правовым и другим общественным законам, наличия управленцев разных уровней от непосредственного создателя благ до государственной власти. Проще говоря, экономическая деятельность всегда сопровождается менеджментом и существует вместе с ним.

Среди разных трактовок упомянутого понятия «экономическая деятельность», которые широко представлены в российской и зарубежной литературе, приведём следующее определение В.И. Дерена: «экономическая деятельность отдельного индивида, предприятия, организации либо органов государственной власти представляет собой реализацию соответствующим из указанных субъектов совокупности открытых или скрытых, активных или пассивных, законных или незаконных действий, связанных с производством, распределением, обменом или потреблением чего-либо в целях извлечения выгод» [3, с. 95].

Из этого определения также легко понять, что экономическая деятельность переплетена с менеджментом как в непосредственном производстве, так и в процессах распределения, обмена и потребления созданных благ, которые требуют определённой организации и управления. Причём, менеджмент можно проследить на всех уровнях экономической деятельности от микро- до макроуровня. а в современных условиях при нарастающем количестве международных, в том числе межгосударственных институтов, таких как ВТО, МВФ, ВБ и других глобализированных управленцев, менеджмент прослеживается во многом от нано- (семейной ячейки) до мега(международного) уровня.

Что касается понятия «предпринимательская деятельность», то его история также прослеживается с древних времён. Например, в Древнем Риме широко использовался термин «mancipium» (манципация), под которым римляне понимали и право собственности, и объект собственности, и процедуру его купли-продажи. В настоящее время в латинском языке используется схожий термин «mancepts», под которым в прошлом понимался подрядчик, а в настоящее время - предприниматель.

Кстати, латинское понятие «mancepts» сформировалось в результате соединения двух самостоятельных терминов: «manus» (рука - насилие - власть - работа - труд - произведение) и «саріо» (приобретать, наследовать, присваивать: прародитель термина «капитал»).

Поэтому под термином «mancepts» понимается категория «предприниматель», а расшифровывается как человек, заработавший капитал своими руками, своим трудом, причём не только упорством, но и хитростью и ловкостью.

По некоторым данным, в XVI веке в Европе предпринимателей называли антрепренёрами, к которым относили организаторов парадов, а также духовных лиц как организаторов и руководителей крупных производственных или строительных проектов, осуществляемых за счёт не собственных, а общественных средств. B XVII веке предпринимателями стали называть лиц, которые заключали с государством контракты на выполнение в определённый период конкретных видов работ или поставку определённой продукции.

Только с XVIII века стали различать собственников капитала и деловых людей (предпринимателей), заставляющих капитал работать и приносить доход.

В современной России широко используются понятия «предпринимательская деятельность» или «предпринимательство». При этом учитывается то, что «предпринимательская деятельность» происходит от французского «activite entrepreneuriale», или от английского - «entrepreneurial activity», а «предпринимательство» от французского «еntreprise» или от английского - «business». Важно отметить, что между указанными понятиями и бизнесом в французской и английской терминологиях ставится знак равенства.

В теории менеджмента и предпринимательства для более полной характеристики наряду с понятием «предприниматель» некоторыми авторами применяются термины «бизнесмен», «капиталист», «рантье» [5, с. 190].

Однако в российских источниках бизнес и предпринимательская деятельность часто всё же различаются. Часть авторов бизнесом признают индивидуальную деятельность субъекта, направленную на обеспечение своего благополучия - самых оптимальных для него условий существования. Другие же исследователи рассматривают бизнес как процесс и как объект. Под бизнесом как процессом они понимают организованные усилия людей по производству и (или) продаже товаров и услуг, удовлетворяющих потребности общества с целью получения прибыли. А под бизнесом как объектом подразумевают совокупность предприятий, организаций и их объединений, действующих под единым руководством, принадлежащих или аффилированных одному лицу и служащих реализации целей определенного субъекта или их группы.

На наш взгляд, бизнес - это обмен экономической деятельностью между деловыми людьми или хозяйствующими субъектами, предполагающий стремление каждого участника сделки реализовать свой личный инте- 
рес, проявление личной или коллективной творческой инициативы в реализации сделки, а также его способность и готовность идти на риск ради проведения сделки на выгодных условиях.

С практической точки зрения сравнение понятий «бизнес» и «предпринимательство» можно рассматривать как синонимы.

А с научной точки зрения, между понятиями «бизнес» и «предпринимательство» можно выявить некоторые различия. В организации бизнеса могут участвовать несколько инвесторов в рамках одного предприятия. Однако, бизнес может принадлежать одному инвестору в рамках нескольких предприятий, например, в рамках холдинговой компании. Поэтому понятие «бизнес» не тождественно понятию «предпринимательство». Предпринимательство связано с организационно-правовыми формами управления, а бизнес со структурой собственности.

Но вернёмся к понятию «предпринимательская деятельность», которое, на наш взгляд, появилось вслед за понятиями «деятельность», «хозяйственная деятельность», «экономическая деятельность» и также по-разному определяется множеством исследователей.

Среди многих трактовок этого понятия приведём лишь некоторые.

Предпринимательская деятельность - это:

- вид экономической, хозяйственной деятельности, связанной с предпринимательским риском, новыми подходами к управлению, новаторством, использованием научных достижений, неопределенностью и всегда направлена на систематическое получение прибыли - вид деятельности, неразрывно связанной с такими понятиями, как «предприимчивость», «динамизм», «инициатива», «смелость», «гибкость», «риск» [4 с. 10];

- способ ведения бизнеса на самостоятельной независимой основе с использованием инноваций;

- вид деятельности, который определяет бизнесмен.

Часто предпринимательство рассматривается как самостоятельная, осуществляемая на свой риск деятельность, направленная на систематическое получение, прибыли от пользования имуществом, продажи товаров, выполнения работ или оказания услуг лицами, зарегистрированными в этом качестве в установленном законом порядке.

При этом предприниматель рационально соединяет материальные и людские ресурсы, организует процесс воспроизводства и управляет им на основе предпринимательского риска, экономической ответственности за конечный предпринимательский результат - получение прибыли.

В общем или широком плане предприимчивость характеризуется как форма проявления трудовой, общественной, политической активности личности и означает сознательное, активное отношение к своим обязанностям, творческий, новаторский подход к делу, постоянный поиск лучших решений поставленных задач $[1,89]$.

На наш взгляд, предпринимательская деятельность как экономическая категория представляет собой основанную на частной собственности на средства производства систему экономических отношений, возникающей в связи с самостоятельной, рисковой деятельностью (производство, распределение, отмен или потребление любой формы товаров) индивидов или их групп, направленной на максимизацию прибыли и других выгод.

Анализ показывает, что экономическая и предпринимательская деятельность индивидов имеет общие четы и существенные различия.

К их общим чертам можно отнести следующие: та и другая деятельность предполагает её регулирование - переплетена с менеджментом; сопровождается предприимчивостью, творческим отношением к делу и инновациям; связана с использованием средств производства и рабочей силы; предполагает экономические отношения между людьми по поводу присвоения и использования экономических ресурсов, а также функционирования всего воспроизводственного процесса; предполагает наличие определённых целей; может выступать в форме отдельных индивидов или их групп; может быть официальной и неофициальной, разрешённой и запрещённой, общественно полезной и вредной для общества, в той или иной степени рисковой и т.д.

Но предпринимательская деятельность отличается от экономической тем, что она является составляющей экономической деятельности; всегда предполагает максимизацию прибыли и других, сиюминутных или ожидаемых через определённое время выгод, порой любой ценой; ей в большей степени присущи риски, особенно субъективного происхождения; появилась она и получила распространение с зарождением частной собственности на средства производства и товарного производства; может быть трудовой и нетрудовой; результатом её деятельности всегда являются товары; она не всегда участвует во всех элементах воспроизводственного процесса, а может быть занята лишь в одном из них, например в фазе обмена, то есть в торговле, и т.д. 
Ещё паз подчеркнём, что, и экономическая деятельность, и предпринимательская деятельность переплетены с менеджментом. В центре менеджмента любой деятельности находится менеджер, который должен обладать предприимчивостью, направленной на снижение затрат в непосредственном процессе такой деятельности и продвижении её результатов к конечному потребителю, повышение качества продукции, поиск и формирование новых потребителей и т.д.

Таким образам, под предприимчивостью следует понимать:

а) деловое качество личности менеджера как энергичность, находчивость, изобретательность, практичность, деловитость;

б) умение находить неординарные решения, извлекая максимальную выгоду из каждой конкретной ситуации для себя, коллектива и общества, при соблюдении правовых и моральных норм и наличии риска.

Из анализа биографий предпринимателей (или людей, достигших успеха / мастерства) ключевыми элементами являются:

а) юношеское страстное увлечение или предрасположенность;

б) счастливый случай, дающий возможность применить свои умения на практике;

в) обучение, во время которого демонстрируется энергия и сосредоточенное внимание $[2,59]$.
К тому же менеджер должен обладать стремлением (страстью) овладения мастерством, что позволяет преодолеть (выдерживать) такие сложности, как: сомнения в себе, утомительные часы учения и однообразных упражнений, неизбежные неудачи, подколки, издевки завистников, недоброжелателей и пр.

Важно подчеркнуть, что взаимосвязь экономической, предпринимательской деятельности и менеджмента вовсе не означает их тождественность. Экономическая и предпринимательская деятельность - более широкие явления, особенно по своим функциям. Только в их рамках появляется менеджмент, функции которого могут выполнять сами собственники непосредственного производства благ, они же могут делегировать часть своих функций назначенным, а то и избранным из числа своих работников на определённое время, или передавать, как правило, только часть своих функций по управлению производством наёмным менеджерам. Так или иначе, основные функции менеджмента выполняют собственники непосредственного производства и лишь частично передают их своим менеджерам.

Однако ни предпринимательская, ни любая другая экономическая деятельность, связанная с непосредственным производством благ не может нормально развиваться без рационально выстроенного менеджмента.

Другими словами, менеджмент и его теории развиваются вместе с развитием связанных с ним экономических категорий и наоборот.

\section{ЛИТЕРАТУРА}

1. Гаврилов А.И., Жмачинский В.И. Предпринимательство и предприимчивость: сущность и содержание, схожесть и различия // Вестник ВГАВТ. Вып.58 Н. Новгород. Изд-Во ФГБОУ ВО «ВГУВТ», - 2019. 188 с.

2. Грин Р. Мастер игры.- М.: РИПОЛ классик, - 2015.592 с.

3. Дерен В.И. Основные регуляторы внутренней и внешней экономической деятельности // Актуальные проблемы теории и практики управления: Сборник научны статьей IX Международной научной конференции, 26 ноября 2019 года, Смоленский государственный университет, Курск: Изд-во ЗАО «Университетская книга», 2019, 337 с.

4. Организация предпринимательской деятельности / В.М. Иванов, И.Г. Ильющенко, О.С. Нюркин, А.С. Трошин.—Н. Новгород. Изд-во ФГБОУ В0 «ВГУВТ»,2016. 100 c.

5. Пономарев 0.Б., Светуньков С.Г. Экономика и предпринимательство. — СПб.: Изд-во «Левша. Санкт-Петербург», — 2015. 632 с.

( ) Трошин Анатолий Сергеевич ( tas-berkut@inbox.ru ), Францева-Костенко Елена Евтифеевна ( frank4u@mail.ru ).

Журнал «Современная наука: актуальные проблемы теории и практики» 